\title{
Improvement of power transfer efficiency of hexagonal coil arrays in misalignment conditions
}

\author{
Sianturi Tigor Franky Devano', Taufik Hidayat ${ }^{2}$, Mudrik Alaydrus ${ }^{3}$ \\ ${ }^{1,3}$ Department of Electrical Engineering, Universitas Mercu Buana, Indonesia \\ ${ }^{2}$ Department of Computer Engineering, Universitas Wiralodra, Indonesia
}

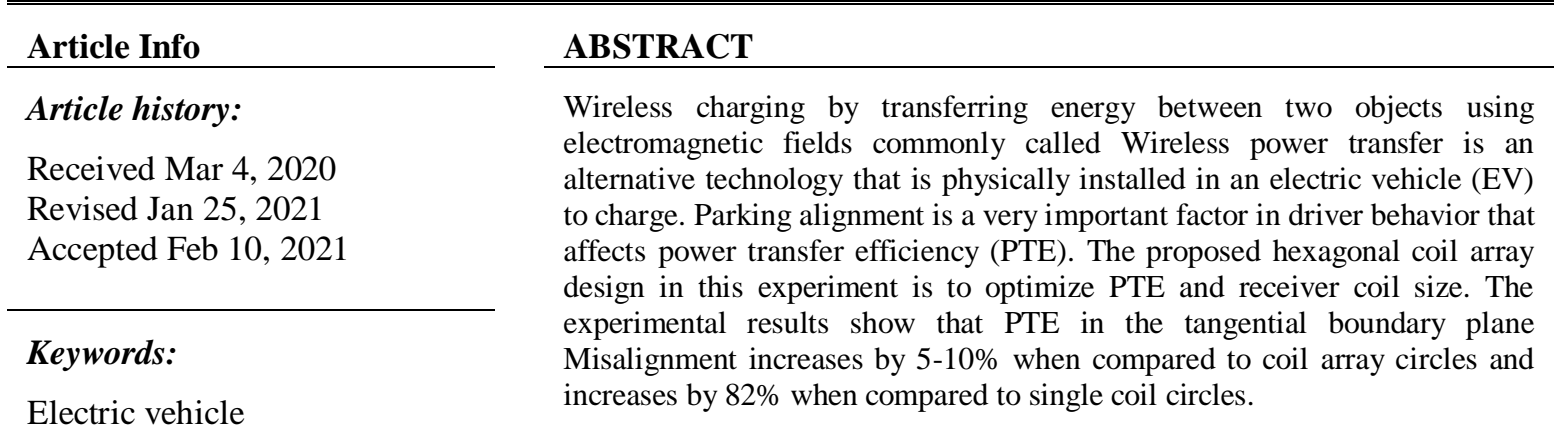

Hexagonal coil array

Inductive power transfer

Misalignment

Power transfer efficiency

This is an open access article under the $\underline{C C B Y-S A}$ license.

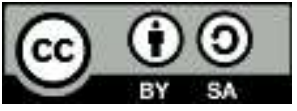

\section{Corresponding Author:}

Taufik Hidayat

Department of Computer Engineering, Universitas Wiralodra

Department of Electrical Engineering, Universitas Mercu Buana, Indonesia

Email: thidayat.ft@unwir.ac.id

\section{INTRODUCTION}

Wireless power transfer (WPT) technology is a promising approach of transferring energy from source to load without physical connection. This technology has been used for a variety of applications including biomedical implants, mining applications, underwater power supplies and electric vehicles with advantages among others not affected by ice, water or other chemicals [1], [2].

Nowadays the demand for high power applications is in an uptrend. Converters on both sides the primary and secondary essentially must be capable of handling the required power level [3]. However, the power capacity of traditional WPT systems was limited by the constraints of semiconductor devices [4]. Additionally, single transmitters and single magnetic couple-based receivers produced low reliability of WPT systems [5] due to only one energy transmission path [6], and may not meet the requirements for high-power applications such as public transport systems that require power to hundreds of KVA or more (up to MW scale) [7], [8]. WPT system applications required high transmission efficiency being despite in large lateral misalignment [9]. One of WPT application systems is the electric vehicle (EV) charging system [10]. WPT for EV applications is divided into: WPT static and dynamic charging [11]. For static scenarios, EV can be charged in a modified car park or garage [12], [8]. In dynamic WPT systems, EV are continuously filled in specific charging lines using railway grid [13], [1]. Battery size may be smaller and reduce capacity by up to $20 \%$ and shorter charging times [14].

Parking behaviour shows that only $5 \%$ of parked vehicles in alignment tolerance for WPT charging can reach $80 \%$ of PTE level. Perfect alignment achieves $95 \%$ of peak efficiency, but peak efficiency will 
decrease less than $50 \%$ in $15-20 \mathrm{~cm}$ misalignment [4]. The WPT technology challenging when efficiency [15], sharply drop down to zero if the distance between transmitter and receiver kept away [16], [5]. That's why many researches in recent years have focused on methods of improving the power transfer efficiency in the EV wireless charging system. The design and location of the coil structure may also affect PTE [17] in EV wireless charging [18], [3].

The misalignment between the transmitter and receiver coils causing the weak coupling thereby reducing efficiency. The existing WPT technology is highly sensitive to the angular and lateral coil misalignment [17]. Recent research with 7 array circle coil design for the transmitter and circle coil receiver can reduce load on EV without reducing the efficiency [2] shown in Figure 1. Misalignment in tangential boundary area causes a drop in efficiency [19]-[20]. The main issue in transfer efficiency due to misalignment and uncoupling between resonance primary coils/transmitter (Tx) with and secondary coil/receiver ( $\mathrm{Rx})$ [21]. In circular Coil Array, the efficiency level will decrease significantly in the tangential boundary area with 7 circular coil arrays, the efficiency drop is close to $0 \%$ [17] with the misalignment position on the central boundary and the tangential boundary is shown in Figure 2. This is become the basis for researchers to conduct studies on the design of other coil shapes in an array, in order to maintain the efficiency level of the tangential boundary. The proposed coil design is a hexagonal coil array.

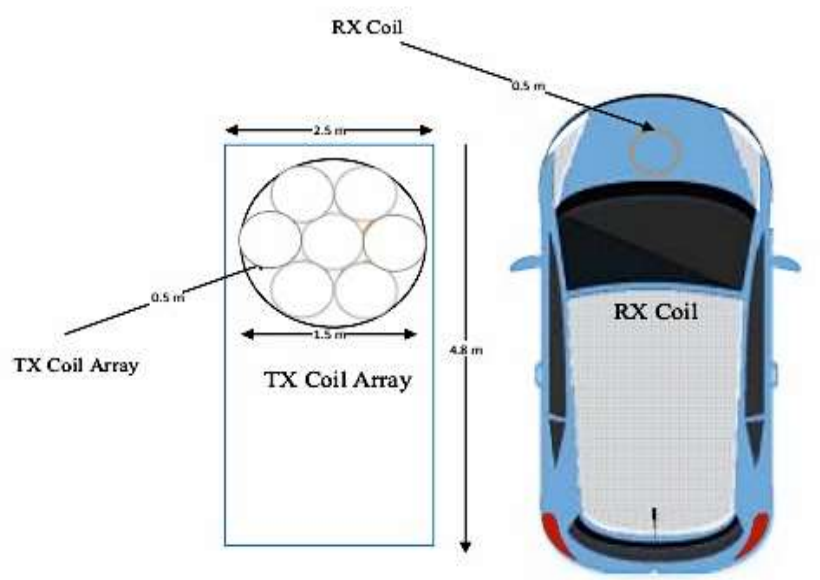

Figure 1. Seven array circle coil design for the transmitter and circle coil receiver



Figure 2. Central Boundary and tangential boundary

This study aims to analyze the energy efficiency when using hexagonal coil arrays in a larger misalignment position both in the central boundary especially in the tangential boundary [20]. With this proposed coil design make the size of the Rx coil smaller and if it's applied on the EV will reduce the weight of the vehicle itself [1], [21]. Next sections of the paper are as follows. Section 2 shows the design of WPT system and data retrieval method based on misalignment central boundary and tangential boundary. Section 3 contains the experiment result and analyzes and conclusion given in Section 4. 


\section{RESEARCH METHOD}

\subsection{Inductive power transfer}

IPT is based on several inductor whose magnetic flux exchanges with each other, where the trasmitter (Tx) coil by the number of turns N1 is driven by a voltage source (or current) and receiver (Rx) coil with the number of turns $\mathrm{N}_{2}$ connected to the load. The mutual inductance between two circular loops separated by distance $d$ with coil turns n1,n2, radius coil r1, r2, as shown in Figure 3, can be calculated using the Neumann equation [22] :

$$
M=\frac{\mu \pi n_{1} n_{2}^{2} r_{1}^{2} r_{2}^{2}}{\left.\left[r_{1}+r_{2}\right)^{2}+d^{2}\right] \sqrt{\left(r_{1}+r_{2}^{2}\right)^{2}+d^{2}}}
$$



Figure 3. Two coil with distance $d$ and radius $r 1$ and $r 2$ [23]

In the medium-distance IPT system power transfer efficiency hence required a high frequency. But when using high frequency, the impedance becomes more inductive [24], causing the power factor (PF) to be smaller. Additional capacitive are required which will cause the impedance to be purely resistive [12]. The addition of capacitors in the circuit causes the coils to resonate at the same frequency in two systems so that the power transfer becomes efficient [13]. Resonance is the tendency of systems (usually linear systems) to oscillate with greater amplitude at some frequencies than others. This is known as the resonant frequency of the system [11]. The quality factor (Q-factor) indicates the stored energy of the oscillator is relatively to the energy loss rate. In ideal series RLC circuit Q factor can be written as shown the following formula [14]:

$$
Q=\frac{1}{R \sqrt{\frac{L}{C}}}
$$

efficiency of WPT system is given [15]:

$$
\eta \max \approx \frac{(k Q)^{2}}{1+\sqrt{\left(1+(k Q)^{2}\right)}}
$$

\subsection{Alignment in WPT}

Perfect alignment occurs when the transmitter coil and receiver coil are aligned at a distance d. The position of misalignment is an important factor that affects PTE as shown in Figure 4. Misalignment consists of two types:

a. Lateral misalignment: when a pair of transmitter coil and receiver coil in parallel position, the center has a horizontal distance $\Delta$ and vertical distance $d$ as shown in Fig ure 4(a).

b. Angular misalignment: when the receiver coil $\mathrm{Rx}$ position is at an angle $\theta$ even though it is parallel to the transmitter coil Tx and aligned well as shown in Figure 4(b). 


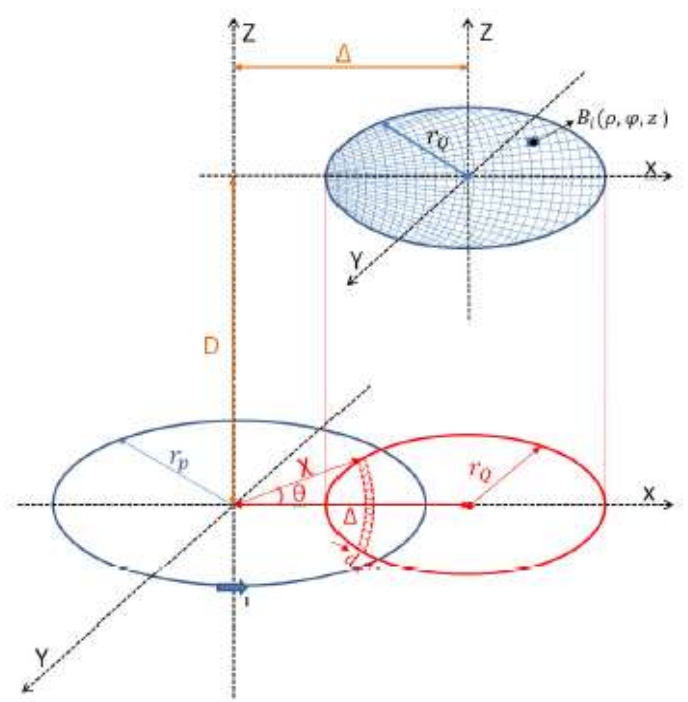

(a) Lateral

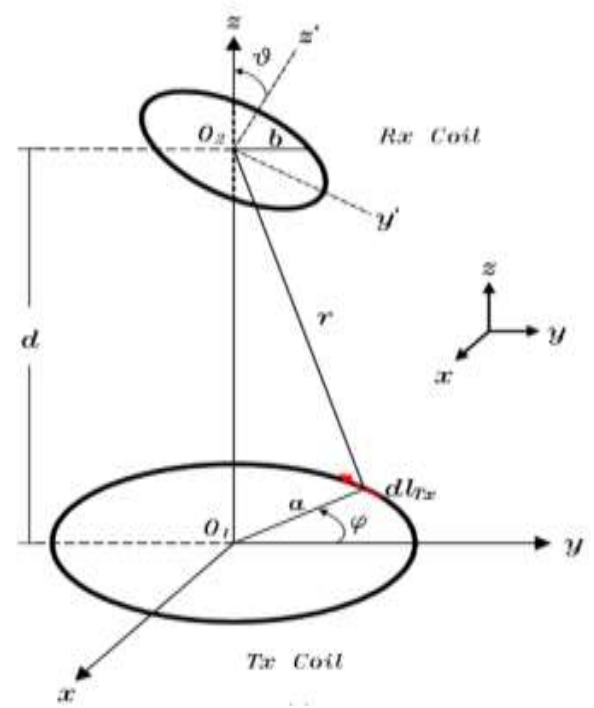

(b) Angular

Figure 4. Misalignment [25]

\subsection{System design}

The design of the system consists of two parts: the transmitter circuit or the primary circuit consisting of a DC power supply unit, a 555 timer in a stable mode, a MOSFET, an LC primary resonance coil and a rectifier and a receiver circuit also called a secondary circuit which consists of secondary resonance coil, rectifier and load in the form [19]. The primary coil resonates at a frequency of about 22.2 $\mathrm{kHz}$ to transfer the induced voltage in the air [24]. When the secondary coil is placed close to the primary coil, due to an electric motion force inducing the secondary coil is then fed to the high frequency rectifier to repair the high frequency AC [26]. Then it was forwarded to the capacitor to filter the noise that occurs on the AC and obtained DC voltage of 12 V. System design can be seen in Figure 5.



Figure 5. System design

\subsection{Coil design}

In order to solve the misalignment issue in tangential boundary [3] a new coil array is proposed in this experiment, which can achieve a higher PTE compared to the single coil benchmark and improve PTE in tangential boundary using 7 array circle coil [27]. Conducting this study in addition to the coil design

Improvement of power transfer efficiency of hexagonal coil arrays in ... (Sianturi Tigor Franky Devano) 
proposed by the researcher [17], it first performs a reconstruction of the coil design [28] of the previous researcher on [8] as a benchmark for measuring and retrieving data [29]. This experiment use 3 coil designs:

a) Single-loop coils with diameter $15 \mathrm{~cm}$ in size as shown in Figure 6(a) for the primary and secondary coils respectively.

b) 7 Arrays Circle coils as reference coils [8] with a diameter of $5 \mathrm{~cm}$ as shown in Figure 6(b) as the primary coil and 1 circle coil with a diameter of $5 \mathrm{~cm}$ as a secondary coil.

c) Proposed coil 7 arrays hexagonal coil with $3 \mathrm{~cm}$ side size as primary coil as shown in Figure 6(c) and 1 hexagonal coil with $3 \mathrm{~cm}$ side size as secondary coil.

Single loop coil as a benchmark, which in general on EV uses one coil on the transmitter and one coil on the receiver.

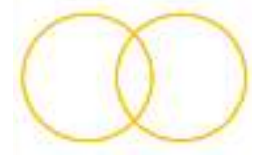

(a) Benchmark coil



(b) 7 Array circle coil

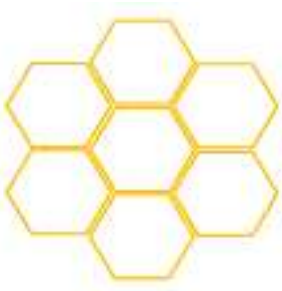

(c) 7 Array hexagonal coil

Figure 6. Coil design

\subsection{Measurement method}

The system was tested by measure using some tool and its function. Reactance, capacitor and resistor was measured using an LCR meter. Voltage and current using multi meter [30]-[31]. The resonant frequency was measured using the oscilloscope. Table 1 gives the summary of dimensions and parameter for each experiment. In this works, Using our system design We measure the PTE of benchmark coil in X/Y axis [29]. Then, reconstruction of the experiment using coil design with 7 array circle coils and the measurements performed on the central boundary and tangential boundary positions [13] as shown in Figure 7. The measured parameters include the voltage and current on the side of the primary coil as well as the secondary coil side.

Figure 8 shows the measurement position of the secondary coil (Rx) to the primary coil (Tx) which is carried out at the center boundary and tangential limit for the arrangement of 7 hexagonal coils. Measurements are made between the primary coil which interacts directly with the secondary coil. It can be seen that the position of the tangential boundary is identical to the position of the center line of the $\mathrm{X}$ axis, so the measurement is carried out according to Figures 8(a) and 8(b). We assume all the misalignments that occur are lateral misalignments.



(a). Central Boundary

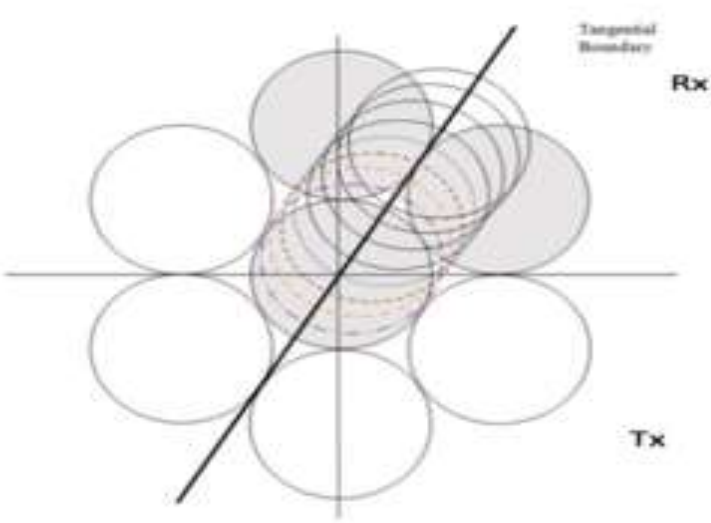

(b). Tangensial Boundary

Figure 7. Measurement position in circle array 7 coils 


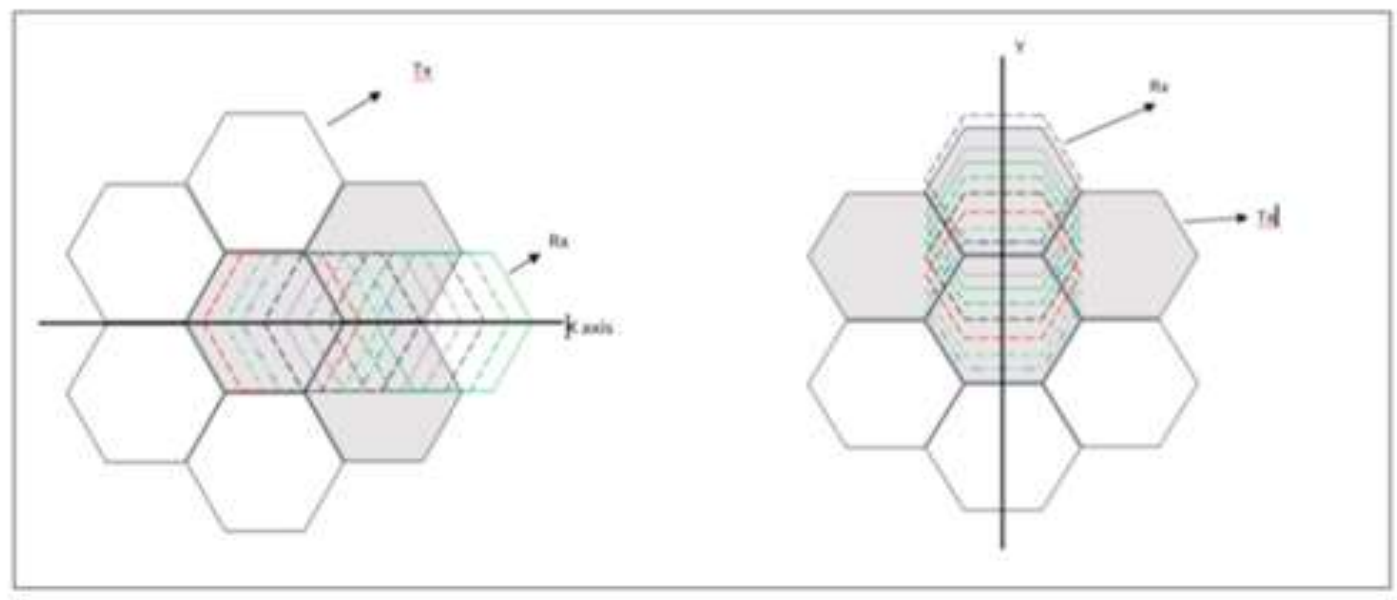

(a). $\mathrm{X}$ axis

(b). $\mathrm{Y}$ axis

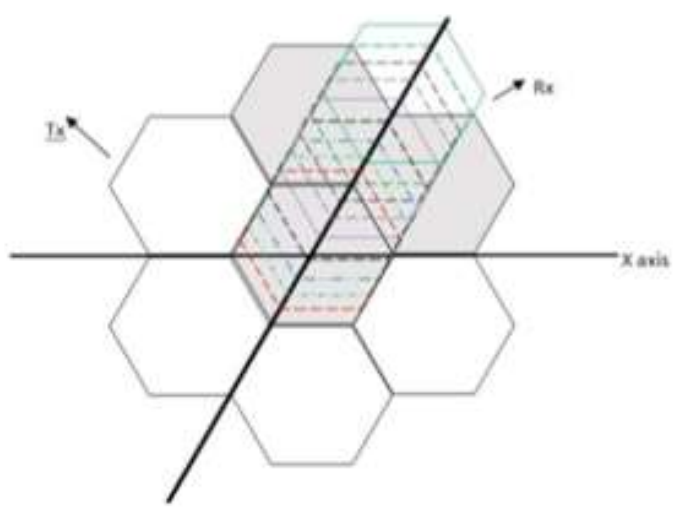

(c). Tangensial Boundary

Figure 8. Measurement position in hexagonal array 7 coils

\section{RESULTS AND DISCUSSION}

Experiment refers to a reference model. An experimental reconstruction with parameters defined by the researcher where the reference results of the reconstructed model are shown in Figure 9(a) and we compare it to the reference coil in Figure 9(b). The efficiency drops by almost 50\% when the angular misalignment is $2 \mathrm{~cm}$ and the efficiency is lost when the misalignment is more than $5 \mathrm{~cm}$. We found that our experiments yielded almost similarities in trends.

Experimental using 7 circle coil arrays, measurements were performed on the central boundary and tangential boundary positions with circle diameters of $5 \mathrm{~cm}$. The result of measurement our 7 Array circles coils show in Figures 9 and 10 compare to measurement result by previous study, it has similarity in trend, both in central boundary and tangential boundary. In the reconstruction of the central boundary measurement, the results in Figure 11(a) show a sharp decrease in the misalignment position from $10 \mathrm{~mm}$ to $15 \mathrm{~mm}$, where the lowest efficiency position occurs at $25 \mathrm{~mm}$ misalignment then rises to the alignment position closer to the closest circle. This happens because the mutual inductance depends on the distance of each coil as in (1).

In Tangential boundary reconstruction, the measurement results in Figure 11 show the same results until the misalignment position is $25 \mathrm{~mm}$ with the measurement center limit due to the same measurement position, but at the tangential boundary position there is an empty gap when the position is more than $25 \mathrm{~mm}$ and the efficiency decreases to $1 \%$. then increased slightly to $10 \%$ when the misalignment position was 45 $\mathrm{mm}$ then decreased to $0 \%$. The increase is experienced when the $35 \mathrm{~mm}$ position becomes $45 \mathrm{~mm}$ from the middle, because in this position there is an effect of mutual inductance by the arrangement of the secondary coil next to the primary coil. 


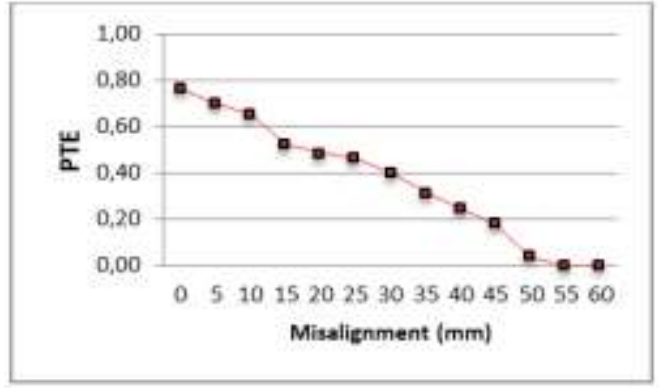

(a) Measurement by researcher

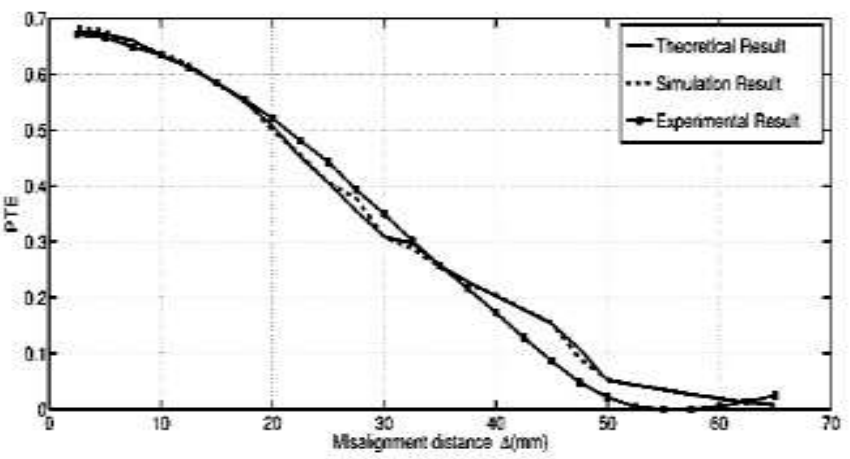

(b) Measurement on previous study

Figure 9. Comparison result benchmark coil [17]

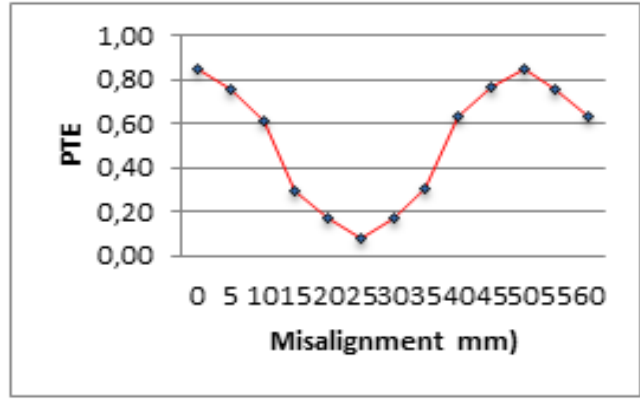

(a) Reconstruction result

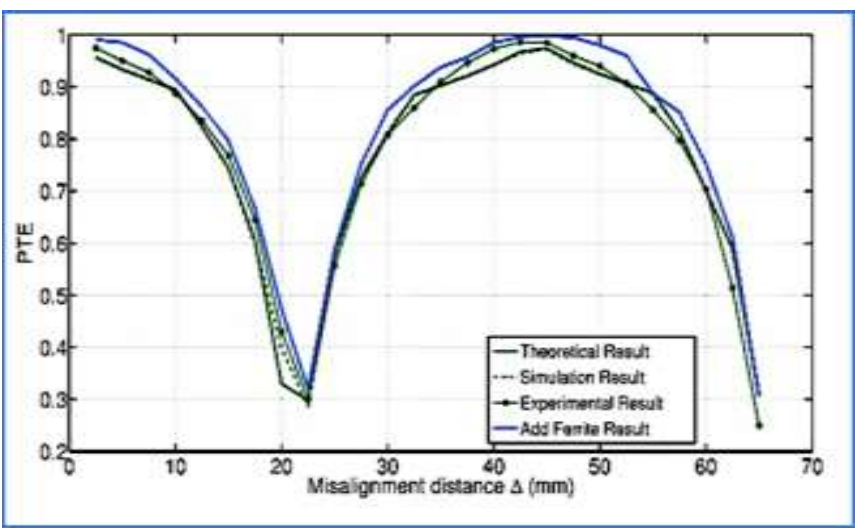

(b) Result central boundary previous study

Figure 10. Comparison result at central boundary

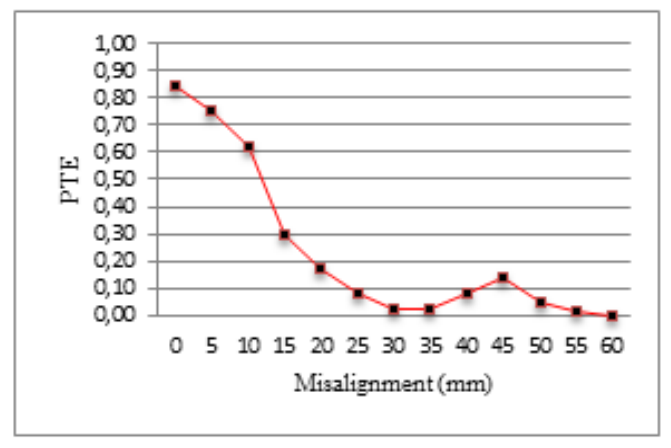

(a) Reconstruction in tangential boundary

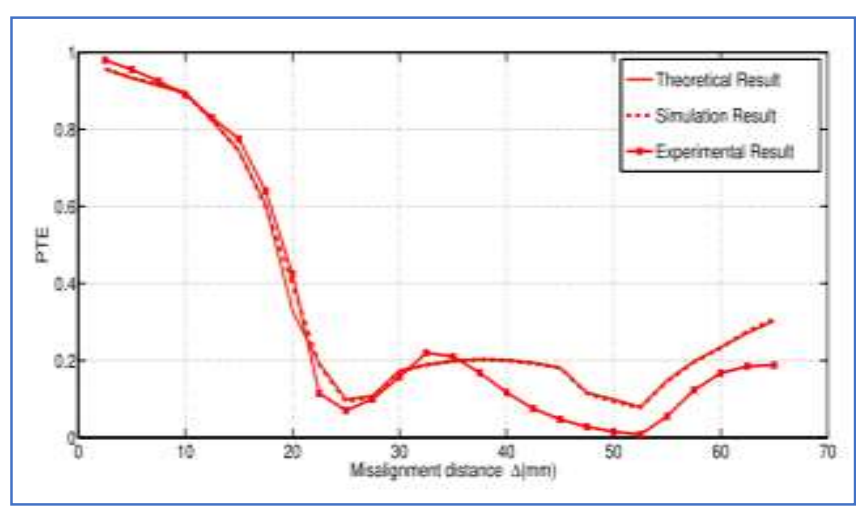

(b) Result Tangential boundary previous study

Figure 11. Comparison result at tangential boundary [8]

From the results of reconstruction above, the system design that we use produces measurements with a trend that is close to the reference both same as 7 array circle coils. So that the measurement with the proposed coil design illustrates the desired improvement. The comparison between 7 array circle coils and 7 array hexagonal arrays in Figure 12 shown that there is not significantly different in central boundary position refers to $\mathrm{Y}$ Axis and it gaves the same position as 7 array circle coils both in $\mathrm{Y}$ axis and $\mathrm{Y}$ axis. 
Unlike the case with the measurement in the tangential boundary position when using 7 array circles coils, the measurement using 7 hexagonal coil arrays shows in Figure 13 that the efficiency at $30 \mathrm{~mm}$ misalignment position stable up to $55 \mathrm{~mm}$ misalignment position with efficiency level up to 2 times from circle coil array at the same position because when using hexagonal arrays coils, there is no empty gap between each coils and the influenced of the mutual inductances still in the scope of each array coils nearest the primary coils maintain the efficiency at the same level, proven by (1).

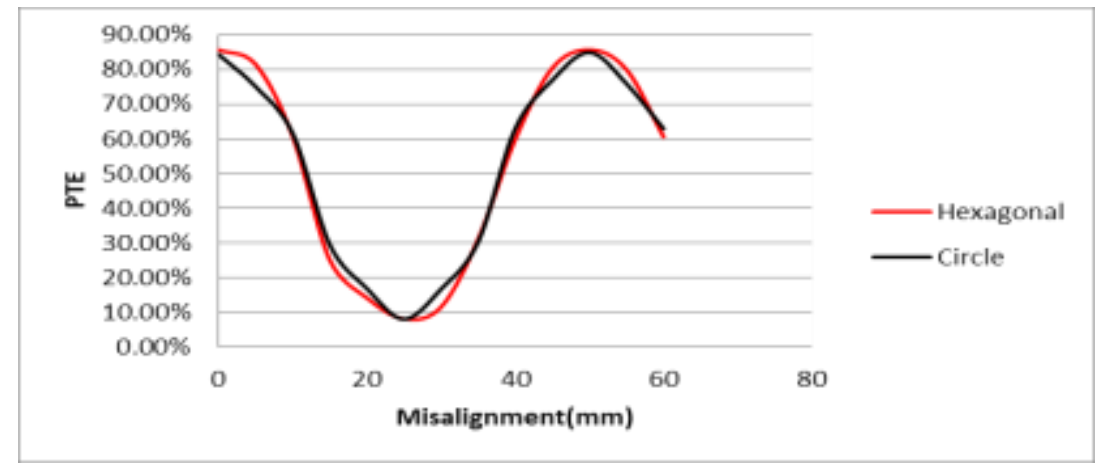

Figure 12. Comparison at central boundary

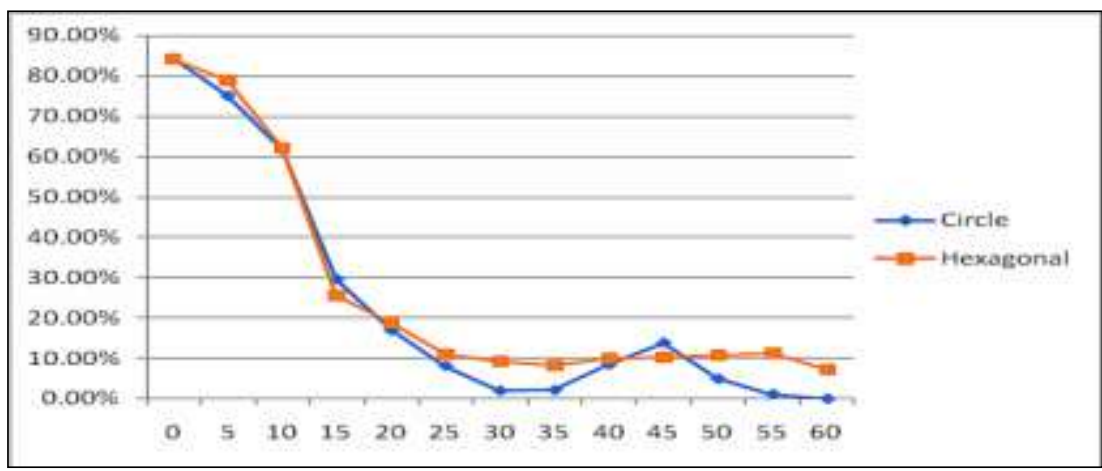

Figure 13. Comparison at tangential boundary

\section{CONCLUSION}

PTE strongly influenced by coil parameters such as its location, dimensions and geometry. This paper has introduced the main resonant coil design of hexagonal array types, to solve misalignment problems in circle array types and achieve higher PTE in boundary tangential position without reducing PTE in central boundary position. In practice related to EV, coil misalignment is unavoidable, as it is difficult for drivers to park their car accurately above a specified charging point or remain within the dynamic filling limit. The experimental results obtained an improvement of PTE observed at the tangential boundary position up to $10 \%$. Furthermore, the array design can reduce the radius of the Rx coil and thus reduce the weight of the car. The comparison between 7 array circle coils with hexagonal arrays is not significantly different in central boundary. Drop in the PTE between coils along the tangential boundary can be optimized by using a hexagonal shaped coil without reducing the maximum misalignment distance between the coils. The coil design presented here only focuses on repairing the PTE associated with coil misalignment and ignoring the losses incurred by additional circuitry required in a complete EV charging system. For Future work, it need to design systems that produce higher power and hardware enhancements to work on the transmitter array positions simultaneously supply energy to the receiver coil without compromising input power requirements.

\section{ACKNOWLEDGEMENTS}

The author like thanks to Department of Electrical Engineering, Universitas Mercu Buana and Department of Computer Engineering, Universitas Wiralodra for support research. 


\section{REFERENCES}

[1] A. El-Shahat, E. Ayisire, Y. Wu, M. Rahman, and D. Nelms, "Electric Vehicles Wireless Power Transfer State-ofThe-Art," Energy Procedia, vol. 162, pp. 24-37, Apr. 2019, doi: 10.1016/j.egypro.2019.04.004.

[2] B. J. Varghese, P. B. Bobba, and M. Kavitha, "Effects of coil misalignment in a four coil implantable wireless power transfer system," in 2016 IEEE 7th Power India International Conference (PIICON), pp. 1-6, 2016, doi: 10.1109/POWERI.2016.8077155.

[3] P. Prag and N. Parspour, "Dynamic charging of electric vehicles demonstrator for contactless energy transfer," in 2017 Brazilian Power Electronics Conference (COBEP), vol. 2018-January, pp. 1-5, 2017, doi: 10.1109/COBEP.2017.8257290.

[4] S. Das Barman, A. W. Reza, N. Kumar, M. E. Karim, and A. B. Munir, "Wireless powering by magnetic resonant coupling: Recent trends in wireless power transfer system and its applications," Renewable and Sustainable Energy Reviews, vol. 51, pp. 1525-1552, Nov. 2015, doi: 10.1016/j.rser.2015.07.031.

[5] D. Klis, S. Burgard, O. Farle, and R. Dyczij-Edlinger, "Fast Simulation of Wireless Power Transfer Systems With Varying Coil Alignment," IFAC-PapersOnLine, vol. 48, no. 1, pp. 248-253, 2015, doi: 10.1016/j.ifacol.2015.05.113.

[6] C. C. M. Siqi Li, "Wireless Power Transfer for Electric Vehicle Application," IEEE Journal of Emerging and Selected Topics in Power Electronics, vol. 3, no. March 2015, pp. 4-17, 2015, doi: 10.1109/JESTPE.2014.2319453.

[7] S. Seshadri, M. Kavitha, and P. B. Bobba, "Effect of coil structures on performance of a four-coil WPT powered medical implantable devices," in 2018 International Conference on Power, Instrumentation, Control and Computing (PICC), pp. 1-6, 2018, doi: 10.1109/PICC.2018.8384805.

[8] J. Chen and H. Tan, "Metamaterial for wireless power transfer system at $13.56 \mathrm{MHz}$ with coil misalignment," in 2017 7th IEEE International Symposium on Microwave, Antenna, Propagation, and EMC Technologies (MAPE), vol. 2018-January, pp. 313-317, 2017, doi: 10.1109/MAPE.2017.8250864.

[9] X. Zhang and H. Zhao, "A four-point quantitative detection method for shafts misalignment," 2016 13th International Conference on Ubiquitous Robots and Ambient Intelligence, URAI 2016, pp. 921-925, 2016, doi: 10.1109/URAI.2016.7734112.

[10] S. Kuzey, S. Balci, and N. Altin, "Design and analysis of a wireless power transfer system with alignment errors for electrical vehicle applications," International Journal of Hydrogen Energy, vol. 42, no. 28, pp. 17928-17939, Jul. 2017, doi: 10.1016/j.ijhydene.2017.03.160.

[11] Z. R. Munggaran and M. Alaydrus, "Efficiency of Wireless Power Transfer System with PWM Methode as Rectifier on Receiver," TELKOMNIKA (Telecommunication Computing Electronics and Control), vol. 16, no. 4, p. 1427, Aug. 2018, doi: 10.12928/telkomnika.v16i4.8046.

[12] X. Liu, W. Han, C. Liu, and P. W. T. Pong, "Marker-Free Coil-Misalignment Detection Approach Using TMR Sensor Array for Dynamic Wireless Charging of Electric Vehicles," IEEE Transactions on Magnetics, vol. 54, no. 11, pp. 1-5, Nov. 2018, doi: 10.1109/TMAG.2018.2844863.

[13] H. Zeng, S. Yang, and F. Peng, "Wireless power transfer via harmonic current for electric vehicles application," Conference Proceedings-IEEE Applied Power Electronics Conference and Exposition-APEC, pp. 592-596, 2015, doi: 10.1109/APEC.2015.7104409.

[14] A. Ahmad, M. S. Alam, Y. Rafat, and S. Shariff, "Designing and demonstration of misalignment reduction for wireless charging of autonomous electric vehicle," eTransportation, vol. 4, p. 100052, May 2020, doi: 10.1016/j.etran.2020.100052.

[15] W. Zhang, J. C. White, A. M. Abraham, and C. C. Mi, "Loosely Coupled Transformer Structure and Interoperability Study for EV Wireless Charging Systems," IEEE Transactions on Power Electronics, vol. 30, no. 11, pp. 6356-6367, 2015, doi: 10.1109/TPEL.2015.2433678.

[16] M. Debbou and F. Colet, "Inductive wireless power transfer for electric vehicle dynamic charging," in 2016 IEEE PELS Workshop on Emerging Technologies: Wireless Power Transfer (WoW), pp. 118-122, 2016, doi: 10.1109/WoW.2016.7772077.

[17] X. Mou, O. Groling, and H. Sun, "Energy-Efficient and Adaptive Design for Wireless Power Transfer in Electric Vehicles," IEEE Transactions on Industrial Electronics, vol. 64, no. 9, pp. 7250-7260, Sep. 2017, doi: 10.1109/TIE.2017.2686299.

[18] S. A. Birrell, D. Wilson, C. P. Yang, G. Dhadyalla, and P. Jennings, "How driver behaviour and parking alignment affects inductive charging systems for electric vehicles," Transportation Research Part C: Emerging Technologies, vol. 58, no. PD, pp. 721-731, Sep. 2015, doi: 10.1016/J.TRC.2015.04.011.

[19] Pingan Tan, Saiqi Cao, and Xieping Gao, "Adjustable coupler for inductive contactless power transfer system to improve lateral misalignment tolerance," in 2016 IEEE 8th International Power Electronics and Motion Control Conference (IPEMC-ECCE Asia), pp. 2423-2426, 2016, doi: 10.1109/IPEMC.2016.7512677.

[20] M. Dama and M. Alaydrus, "Analysis of Multi Coils in Misalignment Conditions in the WPT System," in 2019 International Conference on Radar, Antenna, Microwave, Electronics, and Telecommunications (ICRAMET), pp. 20-23, 2019, doi: 10.1109/ICRAMET47453.2019.8980451.

[21] J. Xu, Y. Xu, and Q. Zhang, "Calculation and analysis of optimal design for wireless power transfer," Computers \& Electrical Engineering, vol. 80, p. 106470, Dec. 2019, doi: 10.1016/j.compeleceng.2019.106470.

[22] X. Lu, P. Wang, D. Niyato, D. I. Kim, and Z. Han, "Wireless Charging Technologies: Fundamentals, Standards, and Network Applications," IEEE Communications Surveys \& Tutorials, vol. 18, no. 2, pp. 1413-1452, 2016, doi: 10.1109/COMST.2015.2499783. 
[23] R. Bhujade, R. Mujavar, P. Singh, B. Joshi, and R. Oruganti, "Modeling and analysis of coupled coils for Wireless Power Transfer," in 2016 IEEE International Conference on Power Electronics, Drives and Energy Systems (PEDES), vol. 2016-January, no. 1, pp. 1-6, 2016, doi: 10.1109/PEDES.2016.7914502.

[24] D. Ustun, S. Balci, and K. Sabanci, "A parametric simulation of the wireless power transfer with inductive coupling for electric vehicles, and modelling with artificial bee colony algorithm," Measurement, vol. 150, p. 107082, 2020, doi: 10.1016/j.measurement.2019.107082.

[25] P. B. Laksono and M. Alaydrus, "Improved Efficiency of Inductive Power Transfer in Misalignment Conditions with Multi Coil Design," Advanced Electromagnetics, vol. 8, no. 1, pp. 30-36, Mar. 2019, doi: 10.7716/aem.v8i1.904.

[26] Y. Li, J. Zhao, Q. Yang, L. Liu, J. Ma, and X. Zhang, "A Novel Coil With High Misalignment Tolerance for Wireless Power Transfer," IEEE Transactions on Magnetics, vol. 55, no. 6, pp. 1-4, Jun. 2019, doi: 10.1109/TMAG.2019.2904086.

[27] J. P. W. Chow, N. Chen, H. S. H. Chung, and L. L. H. Chan, "An Investigation Into the Use of Orthogonal Winding in Loosely Coupled Link for Improving Power Transfer Efficiency Under Coil Misalignment," IEEE Transactions on Power Electronics, vol. 30, no. 10, pp. 5632-5649, Oct. 2015, doi: 10.1109/TPEL.2014.2374651.

[28] S. I. P. and V. O. M. Aderemi A. Atayero, Oluwaseun Ajijola, "Development of a wireless power transfer system using resonant inductive coupling," Lecture Notes in Engineering and Computer Science, vol. 2225, pp. 13-18, 2016.

[29] D. P. Kar, S. S. Biswal, P. K. Sahoo, P. P. Nayak, and S. Bhuyan, "Selection of maximum power transfer region for resonant inductively coupled wireless charging system," AEU-International Journal of Electronics and Communications, vol. 84, no. July 2017, pp. 84-92, Feb. 2018, doi: 10.1016/j.aeue.2017.11.023.

[30] S. Luo, S. Li and H. Zhao, "Reactive power comparison of four-coil, LCC and CLC compensation network for wireless power transfer," 2017 IEEE PELS Workshop on Emerging Technologies: Wireless Power Transfer (WoW), Chongqing, pp. 268-271, 2017, doi: 10.1109/WoW.2017.7959407.

[31] T. Hidayat, S. T. Franky D, and R. Mahardiko, "Energy Efficiency Analysis through Misalignment on New Design of Hexagonal Coil Array in Wireless Power Transfer," International Journal of Integrated Engineering, vol. 12, no. 8, pp. 198-211, Aug. 2020, doi:10.30880/ijie.2020.12.08.019.

\section{BIOGRAPHIES OF AUTHORS}

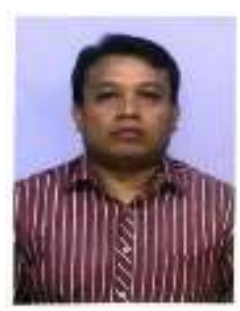

Sianturi Tigor Franky Devano has master degree from Department of Electrical Engineering, Universitas Mercu Buana focused in Wireless Power Transfer. Currency working as a Profesional in IT industry related to Internet of Things, Machine Learning and Fintech.

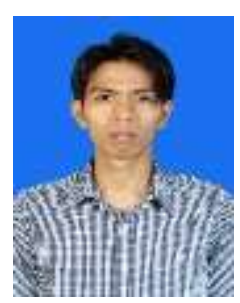

Taufik Hidayat Currently, he is working as lecturer at Department of Computer Engineering, Universitas Wiralodra and doing some researches in IT Value, Blockchain Technology and Internet of Things.

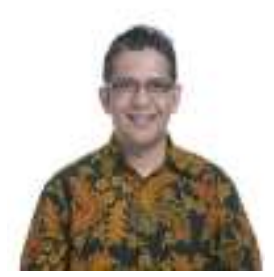

Mudrik Alaydrus currently works at the Electrical Engineering, Universitas Mercu Buana. Mudrik does research in Telecommunications Engineering, Electrical Engineering and Electronic Engineering. His current projects are 1. Millimeterwave Filters and Antennas 2. Interaction between Electromagnetics and Materials 3. Signal Processing in Biometrics. 